\title{
Comportamento de HeRbicidas COM EFEITO Residual EM Diferentes Coberturas na CUltura do FeiJoeiro ${ }^{1}$
}

\author{
Performance of Residual Herbicides Applied in Pre Planting in Dry Bean Crop \\ COBUCCI, T. ${ }^{2}$, PORTELA, C.M.O. ${ }^{3}$, SILVA, W. ${ }^{4}$ e NETO MONTEIRO, A. ${ }^{5}$
}

\begin{abstract}
RESUMO - O objetivo deste trabalho foi avaliar o comportamento de herbicidas com efeito residual em diferentes tipos de cobertura vegetal no sistema plantio direto, antes da semeadura do feijoeiro. Cada herbicida foi aplicado isoladamente em cinco diferentes coberturas, totalizando 20 ensaios. Os herbicidas e as respectivas doses, em $\mathrm{kg} \mathrm{ha}^{-1}$, foram: diclosulan $(0,0125)$, sulfentrazone $(0,300)$, dimethenamid $(1,125)$ e S-metolachlor $(1,152)$. Em Santo Antônio de Goiás utilizou-se a cobertura de Pennisetum glaucum seco e plantas daninhas secas (Commelina benghalensis e Bidens pilosa) no Sistema Integrado de Controle (SIC); e na localidade de Santa Helena de Goiás empregou-se a cobertura de sorgo seco no SIC e Pennisetum glaucum verde e plantas daninhas verdes (C. benghalensis e $B$. pilosa) no sistema Aplique e Plante, nos anos agrícolas de 1999 e 2000. Cada ensaio constituiu-se de $0,2,4,6,8,10,12,14,16,18$ e $20 \mathrm{t} \mathrm{ha}^{-1}$ de biomassa com diferentes coberturas vegetais, as quais receberam os cinco herbicidas, separadamente, no delineamento inteiramente casualizado, com três repetições. A quantificação dos herbicidas no solo foi determinada em bioensaio, usando-se o Sorghum bicolor como planta-teste. Os resultados obtidos indicaram que diclosulan e sulfentrazone foram encontrados no solo acima de $80 \%$ da dose aplicada, independentemente da quantidade e do tipo da cobertura do solo. Para dimethenamid e S-metolachlor, até aproximadamente $50 \%$ das doses aplicadas foram detectadas no solo com 8 t ha ${ }^{-1}$ de palha.
\end{abstract}

Palavras-chave: bioensaio, Phaseolus vulgaris, herbicida no solo.

\begin{abstract}
The objective of this work was to evaluate the performance of residual herbicides applied pre planting in different vegetal coverings under no-till system before dry bean crop establishment in 1999 and 2000. Each herbicide was applied separately in five different coverings, totaling twenty experiments. The herbicides and respective dosages were: diclosulan $\left(0.0125 \mathrm{~kg} \mathrm{ha}^{-1}\right)$, sulfentrazone $\left(0.300 \mathrm{~kg} \mathrm{ha}^{-1}\right)$, dimethenamid (1.125 $\left.\mathrm{kg} \mathrm{ha}^{-1}\right)$ and S-metolachlor $\left(1.152 \mathrm{~kg} \mathrm{ha}^{-1}\right)$. In Santo Antônio de Goiás, Brazil, Pennisetum glaucum dry plants and dry weeds (Commelina benghalensis and Bidens pilosa) were used under the integrated control system (ICS); and in Santa Helena de Goiás sorghum dry plants were used under the (ICS) system and green Pennisetum glaucum and green weeds (Commelina benghalensis and Bidens pilosa) under the Apply and Sow system in 1999/2000. Each experiment consisted of $0,2,4,6,8,10,12,14,16,18$ e 20 tha ${ }^{-1}$ of biomass of different vegetal coverings, each receiving the five herbicides separately in a completely randomized design, with three replicates. The amount of herbicide left in the soil was determined in a bioassay, with Sorghum bicolor being used as a control plant. The results showed that $80 \%$ of the applied doses of diclosulan and sulfentrazone were present in soil independently of the amount and type of soil covering. For dimethenamid and S-metolachlor, up to 50\% of the amount applied was detected in soils with 8 t ha ${ }^{-1}$ of plant residues.
\end{abstract}

Key words: bioassay, Phaseolus vulgaris, herbicide in soil.

Recebido para publicação em 1.10.2002 e na forma revisada em 17.12.2004.

Pesquisador, D.S., Embrapa Arroz e Feijão, Caixa Postal 179, 75375-000 Santo Antônio de Goiás-GO. ${ }^{3}$ Mestrando em Agronomia, Universidade Federal de Goiás, Caixa Postal 131, 74001-970 Goiânia-GO. ${ }^{4}$ Pesquisador, D.S., Embrapa Arroz e Feijão/CNPq Bolsista, Caixa Postal 179, 75375-000 Santo Antônio de Goiás-GO. ${ }^{5}$ Técnico Agrícola, Embrapa Arroz e Feijão/ BASF, Caixa Postal 179, 75375-000 Santo Antônio de Goiás-GO. 


\section{INTRODUÇÃO}

A cobertura morta contribui, significativamente, no sistema plantio direto para o controle de plantas daninhas, tanto pelo efeito físico quanto pelo efeito alelopático (Almeida, 1988). No manejo da área, a aplicação seqüencial de herbicidas em pré-plantio tem proporcionado atraso e/ou decréscimo da germinação de plantas daninhas devido ao controle do primeiro fluxo de invasoras; somado à aplicação de herbicidas com efeito residual, ocorre, como conseqüência, a redução do uso de herbicidas em pós-emergência (Cobucci \& Portela, 1999).

A eficiência dos herbicidas com efeito residual aplicados em pré-plantio depende de sua capacidade de lixiviar da palha até o solo, da quantidade e tipo de palha, das características físico-químicas das moléculas dos herbicidas e da quantidade de precipitação pluviométrica após a aplicação - esses processos definem a capacidade do herbicida em atingir o solo.

De acordo com algumas pesquisas com herbicidas nas culturas de soja e milho, alguns produtos são retidos na palhada, mesmo ocorrendo chuvas logo após a aplicação, como é o caso do metribuzin (Banks \& Robinson, 1982; Rodrigues et al., 2000a); oryzalin (Banks \& Robinson, 1984); acetalinilidas, como alachlor, acetochlor e metolachlor (Strek \& Weber, 1982; Banks \& Robinson, 1986); e trifluralin (Rodrigues et al., 1998). Outros são facilmente lixiviados para o solo, como é o caso do atrazine (Rodrigues \& Almeida, 1986; Fornarolli, 1997), imazaquin e sulfentrazone, que possuem comportamento semelhante (Rodrigues, 1993; Rodrigues et al., 1998, 2000a).
Diante do exposto, a pesquisa teve como objetivo avaliar o comportamento de herbicidas com efeito residual em diferentes tipos de cobertura no sistema plantio direto, antes da semeadura do feijoeiro.

\section{MATERIAL E MÉTODOS}

Foram conduzidos ensaios em Santa Helena de Goiás-GO, num Latossolo Roxo eutrófico, e em Santo Antônio de Goiás-GO, num Latossolo Vermelho-Amarelo, nos anos agricolas de 1999 e 2000. As características químicas e físicas do solo, das áreas experimentais, estão apresentadas na Tabela 1 .

Os herbicidas com efeito residual diclosulan $(0,0125)$, sulfentrazone $(0,300)$ dimethenamid $(1,125)$ e S-metolachlor $(1,152)$, em kg ha-1 - foram aplicados separadamente em cinco diferentes coberturas, totalizando 20 ensaios. Em Santo Antônio de Goiás utilizou-se a cobertura de milheto seco e plantas daninhas secas (Commelina benghalensis e Bidens pilosa) no Sistema Integrado de Controle (SIC); e na localidade de Santa Helena de Goiás empregou-se a cobertura de sorgo seco no SIC e de milheto verde e plantas daninhas verdes $(C$. benghalensis e $B$. pilosa) no sistema Aplique e Plante.

Para obtenção da cobertura seca, a biomassa foi dessecada com sulfosate $\left(0,720 \mathrm{~kg} \mathrm{ha}^{-1}\right)$ aos 20 dias antes da semeadura do feijoeiro. Os herbicidas com efeito residual foram aplicados sobre cobertura seca imediatamente após a semeadura do feijoeiro. Na cobertura verde fez-se aplicação conjunta de herbicidas com efeito residual e sulfosate (720 $\left.\mathrm{g} \mathrm{ha}^{-1}\right)$, sete dias antes semeadura.

Cada ensaio constituiu-se de $0,2,4,6,8$, $10,12,14,16,18$ e $20 \mathrm{t} \mathrm{ha}^{-1}$ de biomassa com

Tabela 1 - Características químicas e físicas das amostras de solo de Santo Antônio de Goiás e Santa Helena de Goiás-GO, 2000

\begin{tabular}{|c|c|c|c|c|c|c|}
\hline \multirow{2}{*}{ Local } & $\mathrm{pH}$ & M.O. & CTC & Argila & Silte & Areia \\
\hline & & $\left(\mathrm{g} \mathrm{kg}^{-1}\right)$ & $\left(\mathrm{Cmol}_{\mathrm{C}} \mathrm{kg}^{-1}\right)$ & \multicolumn{3}{|c|}{$\left(\mathrm{g} \mathrm{kg}^{-1}\right)$} \\
\hline Santo Antônio de Goiás & 5,4 & 21 & 7,98 & 430 & 215 & 355 \\
\hline Santa Helena de Goiás & 5,7 & 32 & 9,97 & 410 & 250 & 340 \\
\hline
\end{tabular}


diferentes tipos de cobertura vegetal por herbicida. Foram realizadas análises de regressão para cada ensaio, tendo como variável independente a quantidade de cobertura $\left(\mathrm{t} \mathrm{ha}^{-1}\right) \mathrm{e}$, como a varíavel dependente, a porcentagem de lixiviação. Foram ajustados os modelos polinomiais, sendo os coeficientes testados pelo teste t a $5 \%$ de probabilidade. O modelo escolhido foi o que obteve todos os coeficientes ou pelo menos o de maior grau - significativos, sendo o $\mathrm{R}^{2} \mathrm{o}$ mais alto possivel e o termo independente da regressão, não-significativo. O delineamento utilizado foi o inteiramente casualizado, com três repetições.

Os herbicidas foram aplicados com um pulverizador costal pressurizado a $\mathrm{CO}_{2}$, equipado com barra de quatro bicos $110015^{2} \mathrm{DG}$, espaçados de $0,50 \mathrm{~m}$, totalizando 2,0 $\mathrm{m}$ de largura efetiva. A pressão utilizada foi de $270 \mathrm{kPa}$ e o volume de calda, de $200 \mathrm{~L} \mathrm{ha}^{-1}$. Após 24 horas da aplicação dos produtos efetuou-se irrigação com 20 mm de lâmina de água em duas horas; depois de 72 horas também fez-se irrigação com o mesmo volume de lâmina de água.

Cinco dias após aplicação dos herbicidas, para cada tratamento, foram coletadas amostras de solo em área de 0,25 m à profundidade de 0 a $0,10 \mathrm{~m}$, para determinação da concentração dos herbicidas, por meio de bioensaio, e posterior determinação da porcentagem de lixiviação.

Para o bioensaio utilizaram-se as amostras de solo provenientes do campo, que foram secas ao ar e homogeneizadas, colocando-se $0,750 \mathrm{~kg}$ em vasos com capacidade de $1 \mathrm{~kg}$, em casa de vegetação. Usou-se o sorgo BR 304 como planta-teste, colocando-se cinco sementes pré-germinadas por um período de 36 horas com comprimento de $\pm 3 \mathrm{~mm}$ de radícula, em cada vaso, a $2 \mathrm{~cm}$ de profundidade. O solo foi saturado com água e mantido próximo à capacidade de campo. As plantas foram colhidas aos 15 dias após a emergência, secas por 72 horas a $70{ }^{\circ} \mathrm{C}$ e, em seguida, pesadas. Com base na produção da biomassa seca correspondente aos tratamentos e da testemunha, foram calculadas as porcentagens de crescimento de plantas de sorgo em relação à testemunha.

A concentração dos herbicidas no solo foi determinada por meio das curvas-padrão (Tabela 2), em que amostras de solo nãotratadas foram, separadamente, tratadas com os herbicidas diclosulan, sulfentrazone, dimethenamid e S-metolachlor, para obter as concentrações de 0, 5, 10, 15, 20, 50, 100 e $200 \mu \mathrm{g} \mathrm{kg}^{-1}$. Novamente, o sorgo BR 304 foi usado como planta-teste.

A porcentagem de lixiviação dos herbicidas residuais da cobertura (morta e/ou verde) para o solo foi calculada entre a relação da concentração dos herbicidas, de cada tratamento, com a testemunha (tratamento sem cobertura, em que $100 \%$ do herbicida atingia o solo).

\section{RESULTADOS E DISCUSSÃO}

Para S-metolachlor, observa-se que com o aumento da quantidade de cobertura (verde ou morta) houve decréscimo da quantidade de herbicida lixiviado da cobertura para o solo (Figura 1). Em todos os tipos de cobertura

Tabela 2 - Equações-padrão para determinação da concentração dos herbicidas residuais no solo, em Santa Helena de Goiás e Santo Antônio de Goiás-GO, 1999 e 2000

\begin{tabular}{|c|c|c|c|c|}
\hline Local & Herbicida residual & Cultura & Equação-padrão & \\
\hline \multirow{4}{*}{ Santa Helena de Goiás } & dimethenamid & Sorgo & $\mathrm{Y}=91,4-0,41 \mathrm{x}$ & $r^{2}=0,94$ \\
\hline & sulfentrazone & Sorgo & $Y=102,4-0,72 x+0,00173 x^{2}$ & $\mathrm{R}^{2}=0,98$ \\
\hline & diclosulan & Sorgo & $Y=96,8-1,41 x+0,00502 x^{2}$ & $\mathrm{R}^{2}=0,93$ \\
\hline & S-metolachlor & Sorgo & $Y=94,3-0,348 x$ & $\mathrm{r}^{2}=0,91$ \\
\hline \multirow{4}{*}{ Santo Antônio de Goiás } & dimethenamid & Sorgo & $Y=90,1-0,43 x$ & $r^{2}=0,95$ \\
\hline & sulfentrazone & Sorgo & $Y=101,2-1,01 x+0,00285 x^{2}$ & $\mathrm{R}^{2}=0,97$ \\
\hline & diclosulan & Sorgo & $Y=101,4-1,63 x+0,00588 x^{2}$ & $\mathrm{R}^{2}=0,94$ \\
\hline & S-metolachlor & Sorgo & $\mathrm{Y}=101,9-1,29 \mathrm{x}+0,00433 \mathrm{x}^{2}$ & $\mathrm{R}^{2}=0,95$ \\
\hline
\end{tabular}

$* \mathrm{y}=$ porcentagem de crescimento de plantas de sorgo em relação à testemunha; $\mathrm{x}=$ concentração de herbicidas no solo (ppb). 
testados com massa de $8 \mathrm{t} \mathrm{ha}^{-1}$, cerca de $50 \%$ desse herbicida atingiu o solo. Entretanto, esses resultados foram diferentes daqueles obtidos por Banks \& Robinson (1986), que verificaram uma lixiviação de menos de 50\% de metolachlor da cobertura com 2,2 t ha ${ }^{-1}$ de palha de trigo para o solo, depois de ter ocorrido $12,5 \mathrm{~mm}$ de chuva logo após a sua aplicação. Rodrigues et al. (2000b) detectaram que o teor de metolachlor no solo era de $43 \%$ do total do produto aplicado na dose normal, após $20 \mathrm{~mm}$ de irrigação e $28,3 \mathrm{~mm}$ de chuva ocorrida 24 horas depois de sua aplicação. Essa diferença entre os resultados pode estar relacionada com a quantidade do volume de lâmina de água usada, que foi de $40 \mathrm{~mm}$.

O comportamento do dimethenamid (Figura 2) foi semelhante ao de S-metolaclhor, demonstrando que, com aproximadamente $10 \mathrm{t} \mathrm{ha}^{-1}$ de cobertura morta, cerca de $50 \%$ do produto deixa de atingir o solo.

De acordo com os resultados obtidos, existe a possibilidade de S-metolachlor e dimethenamid serem usados em aplicações sobre palhada, no Sistema Plantio Direto. O uso vai depender, entretanto, da quantidade dessa palhada e também da espécie de planta daninha a ser controlada, uma vez que, dependendo da intensidade, apenas parte dos herbicidas aplicados atinge o solo. Segundo Rodrigues et al. (2000b), a mistura de metolachlor com atrazine aplicado em pré-emergência na cultura do milho, no Sistema Plantio Direto, sobre a palhada de aveia-preta $\left(3,7 \mathrm{t} \mathrm{ha}^{-1}\right)$, conseguiu atingir o solo com praticamente a metade da dose, e esta, complementada com os efeitos físicos e alelopáticos da palhada, foi eficiente em controlar Brachiaria plantaginea, Euphorbia heterophylla e Bidens pilosa.

Para sulfentrazone, entre 80 e 100\% da quantidade aplicada atingiu o solo, independentemente do tipo de palhada. Esse resultado foi semelhante aos obtidos por Rodrigues et al. (2000a). A facilidade desse produto em ser lixiviado da palhada para o solo, provavelmente, acontece em virtude da boa solubilidade em água (490 ppm). Este herbicida não está registrado para o feijoeiro, porém apresenta-se como uma boa opção para aplicação juntamente com herbicidas aplicados em pré-plantio. Por outro lado, pesquisas sobre a seletividade de doses devem ser realizadas para evitar problemas de toxicidade à cultura. Para soja, além de ser um produto registrado, o seu uso nessa modalidade

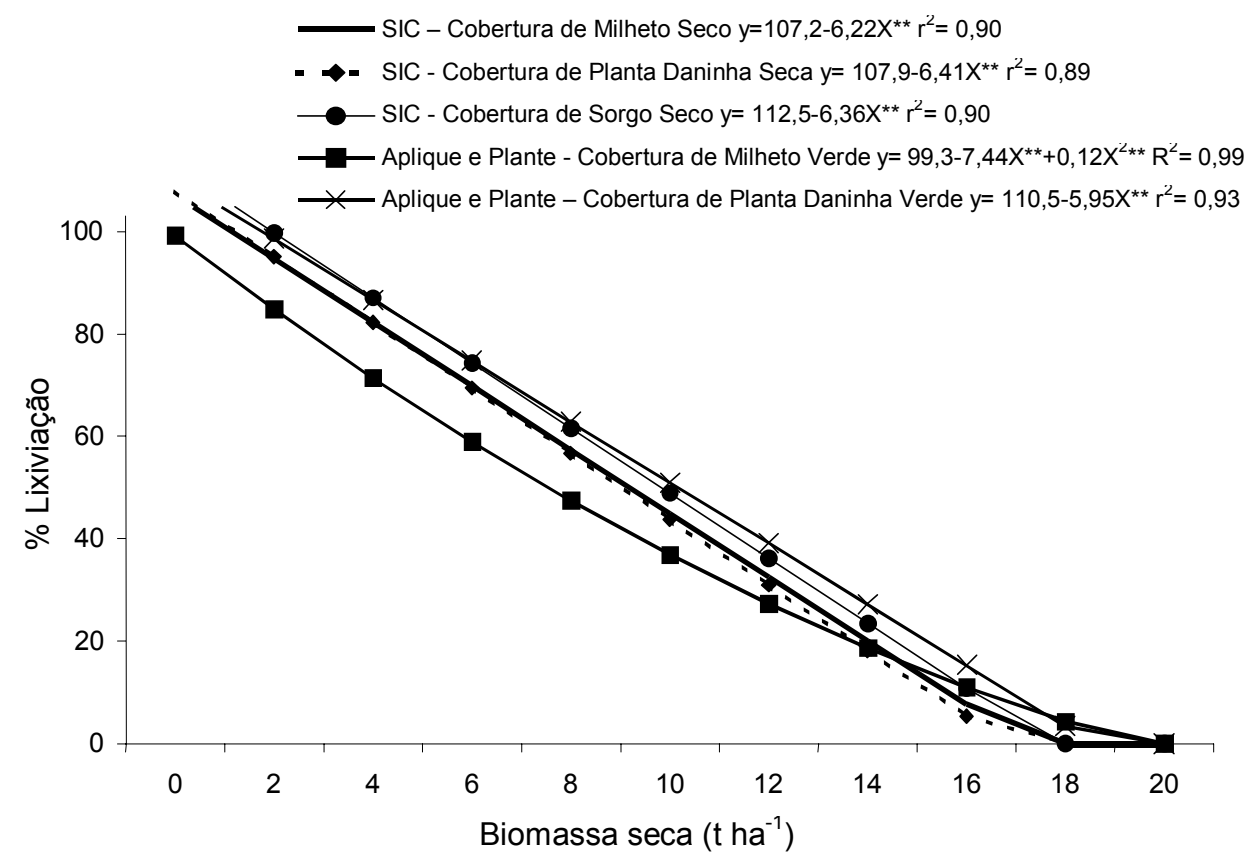

Figura 1 - Lixiviação de S-metolachlor da palhada para o solo, em resposta da biomassa seca de diferentes coberturas do solo. Santo Antônio de Goiás e Santa Helena de Goiás-GO, 2000. 
tem aumentado. Rodrigues et al. (2000a) concluíram que, no Sistema Plantio Direto, a mistura sulfentrazone e metribuzin, aplicada sobre a palhada de aveia-preta $\left(3,7 \mathrm{t} \mathrm{ha}^{-1}\right)$, na modalidade de pré-emergência da soja, conseguiu atingir o solo com praticamente a metade da dose de metribuzin e quase a totalidade de sulfentrazone, o que possibilitou ser este lixiviado eficiente no controle de B. plantaginea, E. heterophylla e B. pilosa.

O diclosulan com a solubilidade em água de 124 ppm também apresentou comportamento semelhante ao do sulfentrazone,

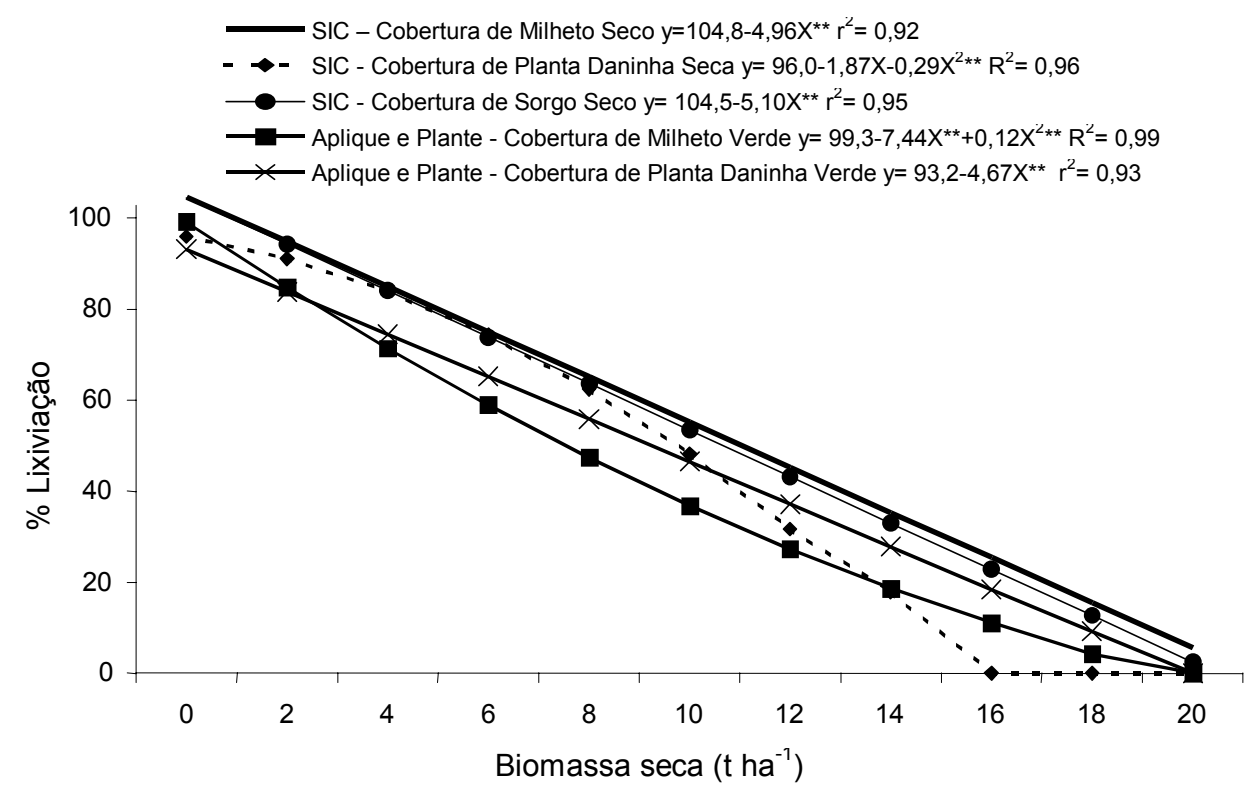

Figura 2 - Lixiviação de dimethenamid da palhada para o solo, em resposta da biomassa seca de diferentes coberturas do solo. Santo Antônio de Goiás e Santa Helena de Goiás-GO, 2000.

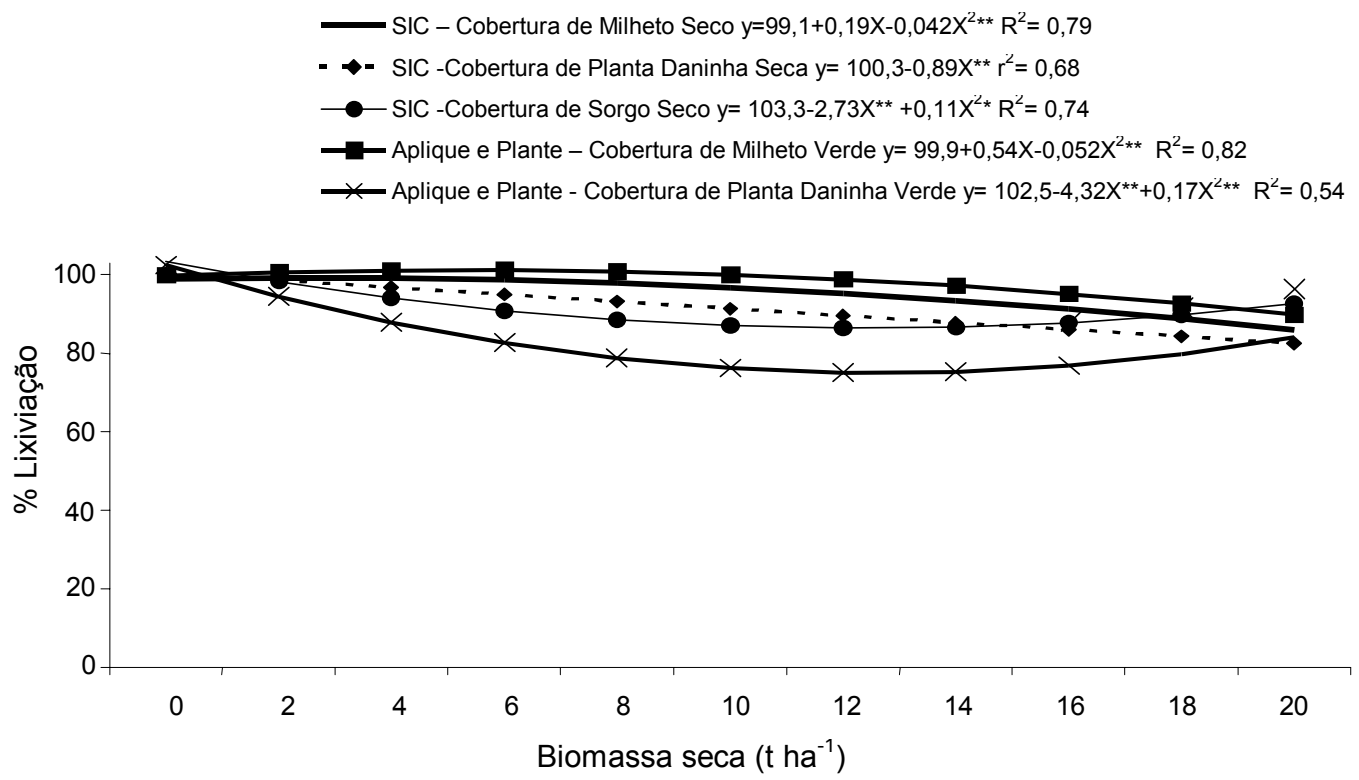

Figura 3 - Lixiviação de sulfentrazone da palhada para o solo, em resposta da biomassa seca de diferentes coberturas do solo. Santo Antônio de Goiás e Santa Helena de Goiás, GO, 2000. 


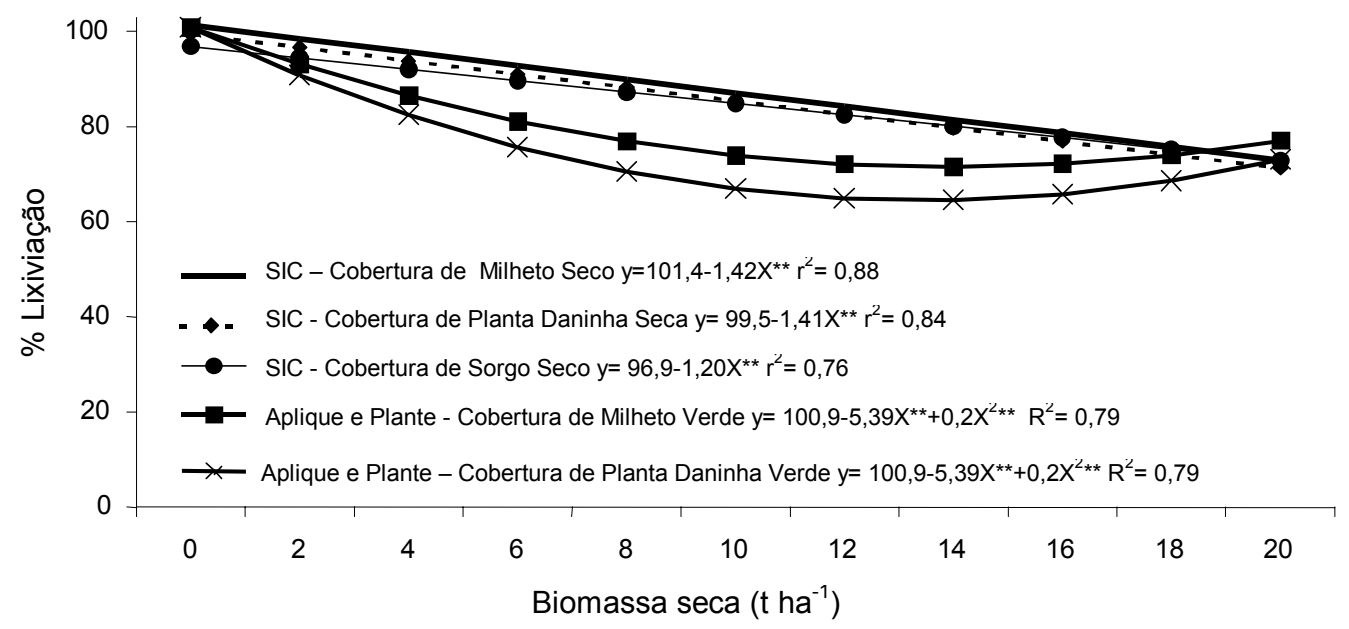

Figura 4 - Lixiviação de diclosulan da palhada para o solo, em resposta da biomassa seca de diferentes coberturas do solo. Santo Antônio de Goiás e Santa Helena de Goiás-GO, 2000.

apesar de a solubilidade ser menor que a do sulfentrazone, ou seja, grande parte do produto foi lixiviada da palhada para o solo, mesmo com grandes quantidades de cobertura. A cobertura verde propiciou uma pequena diminuição da lixiviação (Figura 4). O diclosulan não é registrado para o feijoeiro e acarreta sérias injúrias quando aplicado nas doses recomendadas para a soja; portanto, menores doses devem ser testadas para o feijoeiro.

\section{LITERATURA CITADA}

ALMEIDA, F. S. A alelopatia e as plantas. Londrina: IAPAR, 1988. 60 p. (IAPAR Circular Técnica, 53).

BANKS, P. A.; ROBINSON, E. L. Soil reception and activity of acetochlor, alachlor and metolachlor as affected by wheat (Triticum aestivum) straw irrigation. Weed Sci., v. 34, p. 607-611, 1986.

BANKS, P. A.; ROBINSON, E. L. The fate of oryzalin applied to straw-mulched and non-mulched soils. Weed Sci., v. 32, p. 269-272, 1984.

BANKS, P. A.; ROBINSON, E. L. The influence of straw mulch on the soil reception and persistence of metribuzin. Weed Sci., v. 30, n. 2, p. 164-8,1982.

COBUCCI, T; PORTELA, C. M. O. Aplicação seqüencial de herbicidas aplicados em pré-plantio no controle de plantas daninhas, na cultura do feijoeiro. In: REUNIÃO NACIONAL DE PESQUISA DE FEIJÃO, 1999, Salvador. Resumos expandidos... Santo Antônio de Goiás: Embrapa Arroz e Feijão, 1999. p. 465-468.

Planta Daninha, Viçosa-MG, v. 22, n. 4, p. 591-596, 2004
FORNAROLLI, D. A. Influência da cobertura morta no comportamento do herbicida atrazine. 1997. $69 \mathrm{f}$. Dissertação (Mestrado em Fitotecnia) - Universidade Estadual de Londrina, Londrina, 1997.

RODRIGUES, B. N. Influência da cobertura morta no comportamento dos herbicidas imazaquin e clomazone. Planta Daninha, v. 11, n. 1/2, p. 21-8, 1993.

RODRIGUES, B. N.; ALMEIDA, F. S. Influência da cobertura morta no comportamento dos herbicidas atrazine e metolachlor no sistema direto. In: FUNDAÇÃO INSTITUTO AGRONÔMICO DO PARANÁ, 1986, Londrina. Resultados de pesquisa da Área de Herbologia, safras 1984/1985 e 1985/1986. Londrina: 1986. não publicado

RODRIGUES, B. N.; LIMA, J.; YADA, I. F. U. Retenção pela palhada de herbicidas aplicados em pré-emergência na cultura da soja, em plantio direto. R. Bras. Herb., v. 1, n. 1, $2000 \mathrm{a}$

RODRIGUES, B. N.; LIMA, J.; YADA, I. F. U. Retenção pela palhada de herbicidas aplicados em pré-emergência na cultura do milho, em plantio direto. R. Bras. Herb., v. 1, n. $2,2000 \mathrm{~b}$

RODRIGUES, B. N. et al. Influência da cobertura morta no comportamento do herbicida trifluralin. Planta Daninha, v. 16, n. 2, p. 163-173, 1998.

SKORA NETO, F.; MARQUES, A. Avaliação de paraquat em aplicação seqüencial ao sulfosate na operação em plantio direto na cultura do feijão. In: CONGRESSO BRASILEIRO DA CIÊNCIA DAS PLANTAS DANINHAS, 22., 2000, Foz do Iguaçu, PR. Resumos... Londrina: SBCPD, 2000. p. 236.

STREK, H. J.; WEBER, J. B. Adsorption, mobility and activity comparisons between alachlor (Laço) and metolachlor (Dual). Proc. South. Weed Sci. Soc., v. 35, p. 332-338, 1982 . 